
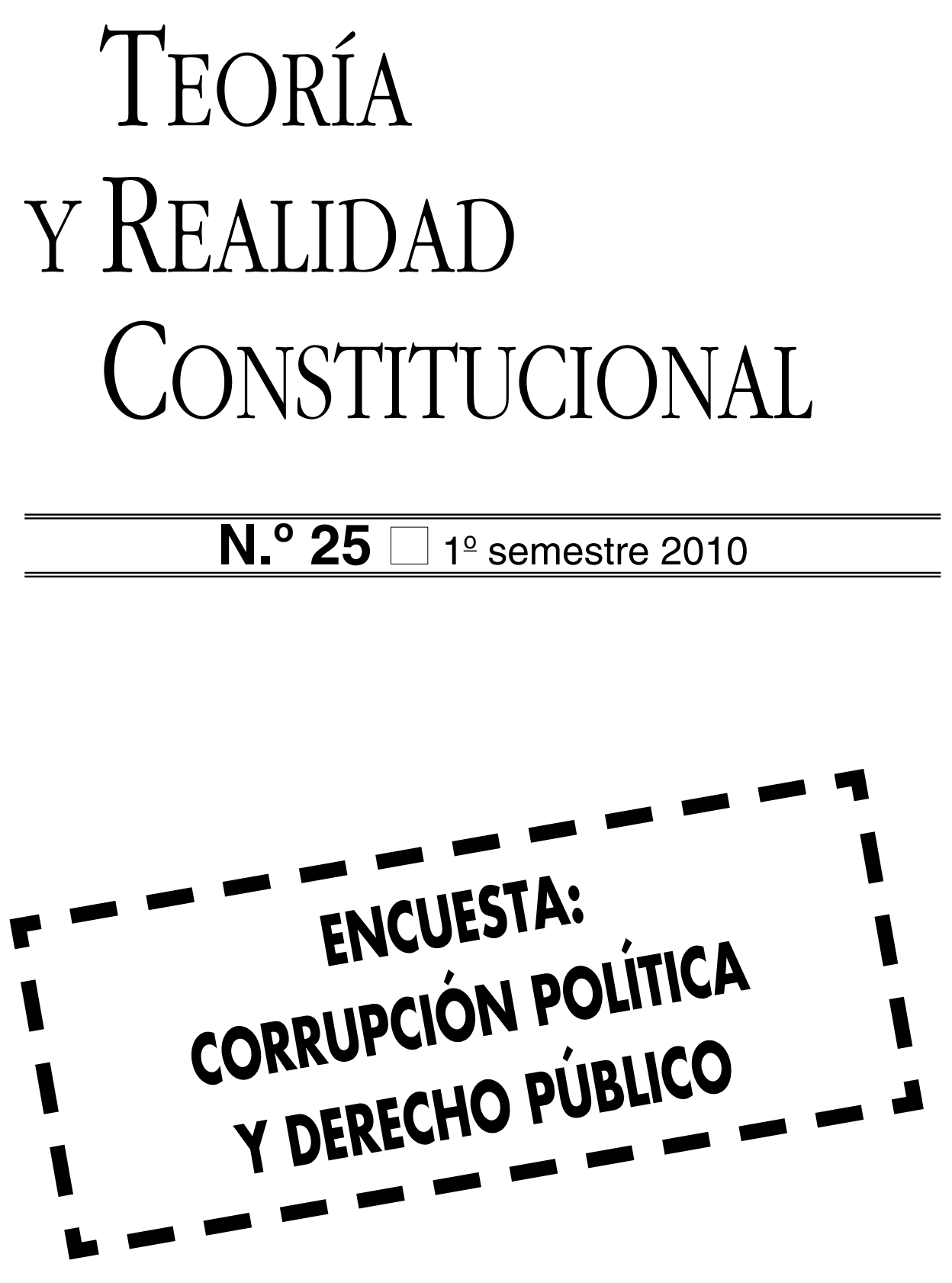


\title{
LA ESPECIAL TRASCENDENCIA CONSTITUCIONAL COMO CONCEPTO JURIDICO INDETERMINADO. DE LA REFORMA DE 2007 DE LA LOTC A LA STC 155/2009, DE 25 DE JUNIO
}

\author{
DAVID ORTEGA GUTIÉRREZ \\ Profesor Titular de Derecho Constitucional \\ Universidad Rey Juan Carlos
}

\author{
SUMARIO \\ I. Introducción. \\ II. La reforma de la LOTC del año 2007 y la \\ saturación del poder corrector. \\ III. El antecedente de los AATC de 2008 y la \\ STC 70/2009, de 23 de marzo. \\ IV. La determinación del concepto en la \\ STC 155/2009, de 25 de junio. \\ V. Conclusiones.
}

\section{INTRODUCCIÓN}

En el presente artículo se va abordar el análisis jurídico de una cuestión ciertamente compleja, relacionada con la reforma de la Ley Orgánica 2/1979, de 3 de octubre, del Tribunal Constitucional (LOTC), llevada a cabo por el Parlamento español, a través de la Ley Orgánica 6/2007, de 24 de mayo. Concretamente nos centraremos en el nuevo procedimiento de admisión de la demanda de amparo, y más específicamente en la modificación de los artículos $49.1^{1}$ y

1 Art. 49.1: «El recurso de amparo constitucional se iniciará mediante demanda en la que se expondrán con claridad y concisión los hechos que la fundamenten, se citarán los preceptos constitucionales que se estimen infringidos y se fijará con precisión el amparo que se solicita para preservar o restablecer el derecho o libertad que se considere vulnerado. En todo caso, la demanda justificará la especial trascendencia constitucional del recurson. En cursiva aparece la nueva frase que añade la reforma de la LOTC de 2007. 
50.1.b) $)^{2}$ de la LOTC y en lo que significa la nueva expresión «especial trascendencia constitucional", que será el nuevo requisito esencial para admitir o no el recurso.

Sin duda nos encontramos ante un concepto jurídico indeterminado ${ }^{3}$, materia que desde el ámbito del derecho constitucional no se ha estudiado quizás con la extensión y profundidad que lo ha hecho el derecho administrativo $^{4}$. Partiendo de la teoría de los conceptos jurídicos indeterminados 5 ,

2 Art. 50.1: «El recurso debe ser objeto de una decisión de admisión a trámite. La Sección, por unanimidad de sus miembros, acordará mediante providencia la admisión, en todo o en parte, del recurso solamente cuando concurran todos los siguientes requisitos: [...] b) Que el contenido del recurso justifique una decisión sobre el fondo por parte del Tribunal Constitucional en razón de su especial trascendencia constitucional, que se apreciará atendiendo a su importancia para la interpretación de la Constitución, para su aplicación o para su general eficacia, y para la determinación del contenido y alcance de los derechos fundamentales". La redacción conforme a la reforma del año 2007, cambia totalmente el apartado 1 y la letra b) del mismo, del art. 50.

3 Así lo reconoce la propia STC 155/2009, en su fundamento jurídico $2^{\circ}$ : "El carácter notablemente abierto e indeterminado, tanto de la noción de "especial trascendencia constitucional" [...].

4 Tratando de paliar esta laguna, ver David Ortega Gutiérrez, Los conceptos jurídicos indeterminados en la jurisprudencia constitucional española, Madrid, Dykinson, 2009. La obra de referencia sobre la teoría de los conceptos jurídicos indeterminados sigue siendo el magnífico estudio de Sainz Moreno, Fernando, Conceptos jurídicos, interpretación y discrecionalidad administrativa, Madrid, Civitas, 1976.

5 En relación con los conceptos jurídicos indeterminados desde el análisis puntual de diferentes aspectos jurídicos, ver Chico, Franco, «El interés del menor como concepto jurídico indeterminado", en http://agendamagna.worldpress.com, págs. 1-17; CURELL SUÑOL, M., "Conceptos jurídicos indeterminados en el ámbito de la propiedad industrial" en Estudios sobre propiedad industrial e intelectual y derecho de la competencia. Homenaje a Alberto Bercovitz, Barcelona, AIPPI (Asociación Internacional para la Protección de la Propiedad Industrial), 2005, págs. 321-338; FERNÁNDEZ GARCÍA, $M^{a}$ Y., "El concepto jurídico indeterminado de "servicio esencial" en la Constitución española" en Revista de Administración Pública, n' ${ }^{\circ}$ 170, 2006, págs. 325-338; GARCÍA DE ENTERRÍA, E., "Una nota sobre el interés general como concepto jurídico indeterminado" en Revista Española de Derecho Administrativo, n. ${ }^{\circ} 89$, 1996, págs. 69-89; GONZÁLEZ-TREVIJANO, P., "Conceptos jurídicos indeterminados y realidades económicas difusas en la Constitución de 1978", en L. COSCULLUELA MONTANER (coord.), Estudios de Derecho público económico: libro homenaje al prof. Dr. D. Sebastían Martín-Retortillo, Madrid, Civitas, 2003, págs. 205-218; HORST-EBERHARD, H., La cuestión de hecho, el concepto indeterminado en el derecho civil y su casacionalidad, Buenos Aires, Ediciones jurídicas EuropaAmérica, 1979; JUAN ASENJO, Ó., La Constitución económica española, Madrid, Centro de Estudios Constitucionales, 1984; MARCOS CARDONA, M., "El valor real como concepto jurídico indeterminado" en La comprobación de valores de inmuebles, Madrid, Dijusa, 2002, capítulo 1, págs. 17-33; MORENA Y DE LA MORENA, L. de la, "La seguridad pública como concepto jurídico indeterminado: su concreta aplicación a los traspasos de servicios en materia de espectáculos públicos", en Revista de Administración Pública, 109, enero-abril de 1986, págs. 321-361; PÉREZ VALLÉS, P., "El arraigo como concepto jurídico indeterminado" en www.visae.es; QUADRA-SALCEDO, T., "La Constitución económica de España. Comentario introductorio al Título VII" en Óscar Alzaga (dir.), Comentarios a la Constitución Española de 1978, tomo X, Madrid, Edersa/Cortes Generales, 1998, págs. 15-44; QUINTANA LÓPEZ, T., "Responsabilidad patrimonial de la Administración y conceptos jurídicos indeterminados", en Poder Judicial, números 41-42, págs. 457-466; REAL ALCALÁ, J. A. del, "Sobre la indeterminación del Derecho y la Ley constitucional. El caso del término "nacionalidades" como concepto jurídico indeterminado", en De- 
estudiaremos cómo las diferentes resoluciones del Tribunal Constitucional han ido perfilando este nuevo concepto jurídico nacido de la citada reforma del año 2007. Primero a través de sus Autos, en concreto los siguientes: AATC 188/2008, de 21 de julio, 289 y 290/2008, de 22 de septiembre. Luego de sus Sentencias, con un breve esbozo en la STC 70/2009, de 23 de marzo, y la doctrina más decisiva en la STC 155/2009, de 25 de junio, destacando su fundamento jurídico segundo.

El objeto de estudio, como veremos más adelante, ha generado una interesante controversia, no en balde afecta en última instancia a un tema tan sensible como la protección de los derechos fundamentales, e incluso el contenido del concepto jurídico indeterminado "especial trascendencia constitucional" marcado básicamente por la STC 155/2009, tuvo cierta repercusión mediática $^{6}$ a nivel nacional. Por último, también habremos de abordar cómo se ha llegado a la formación de este concepto jurídico indeterminado, lo cual implica, aunque sea colateralmente, apuntar el iter y los pormenores de la gestación de la reforma de la LOTC del año 2007 en lo que se refiere al procedimiento de admisión de la demanda de amparo.

\section{LA REFORMA DE LA LOTC DEL AÑO 2007 Y LA SATURACIÓN DEL PODER CORRECTOR}

No se entiende bien el sentido del concepto jurídico indeterminado «especial trascendencia constitucional", si previamente no explicamos el contexto y la problemática que, en principio, busca solucionar o, al menos, paliar ${ }^{7}$. Esto nos conduce directamente a los conocidos problemas de saturación o cuasiparalización del Tribunal Constitucional fruto del exceso de demandas de amparo que tiene que resolver ${ }^{8}$ y de la errónea concepción del mismo "Como una instancia procesal más del procedimiento ordinario de tutela,

rechos y Libertades. Revista del Instituto Bartolomé de las Casas, número 11, 2002, págs. 223-25; REDONDO, M. C., "Teorías del Derecho e indeterminación normativa", en Doxa. Cuadernos de Filosofía del Derecho, número 20, CEC-Universidad de Alicante, 1997, págs. 177-196; y RIERA RIBAS, B., "Los conceptos jurídicos indeterminados en la nueva Ley General Tributaria", en Revista de Contabilidad y Tributación, 265, abril de 2005, págs. 33-98.

6 Ver, por ejemplo, $A B C$ de 13 de julio de 2009, pág. 27. En prensa más especializada en el ámbito jurídico, ver Diario del Derecho de 14 de julio de 2009:

www.iustel.com/v2/diario del derecho/noticia.asp?ref iustel=1036762

7 En relación a la racionalización en el uso del recurso de amparo para evitar el colapso del Tribunal, ver, entre otros, P. PÉREZ TREMPS y otros, La reforma del recurso de amparo, Tirant Lo Blanch, Valencia, 2004 y P. CRUZ VILLALÓN, "Qué hacer con el amparo", en Actualidad Jurídica Uría-Menéndez, n 15, 2006, págs. 6-13.

8 Aparte lógicamente de las Memorias anuales del Tribunal Constitucional, respecto de una síntesis útil de la situación real del Tribunal Constitucional en los años previos a la reforma de la LOTC de 2007 —esto es, años 2002-2006—, ver A. DE LA OLIVA SANTOS, "La perversión jurídica del amparo constitucional en España" en www.ucm.es/info/procesal/revista/perversion.htm, págs. 8-13. 
que no como una vía especial para su protección" ${ }^{9}$. De sus tres principales funciones constitucionales (art. 161.1 y $163 \mathrm{CE}$ ): control de constitucionalidad, recurso de amparo y conflicto de competencias, es de largo las demandas de admisión del recurso de amparo constitucional las que mayor tiempo, esfuerzo y medios personales y materiales requieren del Tribunal Constitucional ${ }^{10}$. La propia exposición de motivos de la LO $6 / 2007^{11}$ en su segundo apartado así nos lo indica: "La experiencia acumulada tras más de 25 años de actividad del Tribunal Constitucional desde su creación ha puesto de manifiesto la existencia de una serie de situaciones y circunstancias en la realidad práctica que con el transcurso del tiempo han llegado a convertirse en problemas para el mejor resultado del trabajo del Tribunal. Entre ellas destaca, por un lado, el crecimiento del número de recursos de amparo hasta el punto de ocupar casi todo el tiempo y los medios materiales y personales del Tribunal. Por otro lado, la realidad de los hechos ha permitido también constatar la lentitud de los procedimientos que se desarrollan ante este Alto Tribunal, cuestiones todas ellas respecto de las que es el momento de dar respuesta legislativa. En este sentido, esta ley orgánica intenta dar solución a todo este conjunto de problemas, y para ello procede a adecuar la normativa para dar respuesta a los problemas y exigencias que se derivan de la realidad práctica del funcionamiento y organización del Tribunal Constitucional ${ }^{12}$. El Ministerio de Justicia en su día publicó un documento explicando los objetivos de la reforma de 2007 de la LOTC, indicando que buscaba "facilitar que el Tribunal Constitucional pueda realizar mejor su trabajo en la garantía de la Constitución y en la defensa de los derechos de los ciudadanos. Con este fin se llevará a cabo una reforma específica en su organización y una serie de

9 Ver M. CARRILLO (Coord.), Hacia una nueva jurisdicción constitucional. Estudios sobre la ley 6/2007, de 24 de mayo de reforma de la LOTC, Valencia, Tirant Lo Blanch, 2008, pág. 101.

10 La Memoria del Tribunal Constitucional del año 2006, por ejemplo, de un total de 11.741 asuntos judiciales —el año anterior fueron 9.708- 11.471 fueron recursos de amparo, es decir, un $97,70 \%$. Los 270 asuntos restantes fueron 23 recursos de inconstitucionalidad, 237 cuestiones de inconstitucionalidad y 10 conflictos positivos de competencia.

11 Sobre la tramitación de la misma, ver M. PULIDO QUECEDO, "Apunte sobre la tramitación de la reforma de la LOTC", en Repertorio Aranzadi del Tribunal Constitucional, nº 1, 2007, págs. 9-11.

12 Más extensamente, sobre este mismo argumento, señala el apartado tercero de la exposición de motivos: "El elevado número de demandas de amparo ha provocado un amplio desarrollo de la función de garantía de los derechos fundamentales en detrimento de otras competencias del Tribunal Constitucional. El número de solicitudes de amparo y el procedimiento legalmente previsto para su tramitación son las causas que explican la sobrecarga que en la actualidad sufre el Tribunal a la hora de resolver estos procedimientos de garantía de los derechos fundamentales. Por esta razón, las reformas que se abordan van dirigidas a dotar al amparo de una nueva configuración que resulte más eficaz y eficiente para cumplir con los objetivos constitucionalmente previstos para esta institución. Y así, entre las modificaciones que se introducen en relación con el amparo se pueden destacar el cambio en la configuración del trámite de admisión del recurso, la habilitación a las Secciones para su resolución y la reforma del trámite de cuestión interna de constitucionalidad prevista en el artículo 55.2 de la Ley Orgánica 2/1979, de 3 de octubre". 
mejoras técnicas procesales»" ${ }^{13}$. No debemos olvidar, por lo demás, que ya el Legislador de $1988^{14}$ trató sin éxito ${ }^{15}$ de modificar la LOTC en relación con la saturación que el Tribunal Constitucional experimentaba, al reformar el trámite de admisión de los recursos de amparo.

Sin embargo, el riesgo o peligro de la proyectada reforma - hoy ya realidad- era la posible merma que se podría producir en la defensa y protección de los derechos fundamentales de los ciudadanos. La excesiva objetivación - la exigencia de la especial trascendencia constitucional- del amparo podía acabar con el denominado amparo subjetivo, esto es, la defensa efectiva anta la lesión constitucional que sufre el ciudadano. En última instancia, la mayor eficacia y funcionalidad del propio Tribunal no puede implicar la reducción de las garantías de los ciudadanos en cuanto a sus derechos fundamentales y libertades públicas ${ }^{16}$, contempladas expresamente en el Capítulo IV del Título I (arts. 53 y 54), y en lo que se refiere al recurso de amparo, específicamente en el artículo $53.2 \mathrm{CE}$ in fine. No es unánime la doctrina en cuanto a la interpretación de lo señalado por el constituyente en el art. 53.2 CE.

Así, por ejemplo, Lucas Murillo de la Cueva entiende el "en su caso" ${ }^{17}$ del art. 53.2 en los siguientes términos: "Por tanto, en principio, es constitucionalmente posible excluir el recurso de amparo ante el Tribunal Constitucional en algunos supuestos. Del mismo modo, el margen del que dispone para circunscribir su admisión es muy amplio" ${ }^{18}$. Jiménez Campo también estudia la interpretación del "en su caso" especialmente desde la vertiente objetiva del recurso, y al respecto nos indica que «el legislador puede, por ejemplo, construir el amparo como recurso exclusivamente dirigido frente a actos u omi-

13 Ver www.juecesdemocracia.es/actualidadMJU/2005/noviembre/cuadroproyecto reformaLOTC.pdf

Ver pág. 2. Más adelante indica, respecto de la nueva regulación de la admisión del recurso de amparo, lo siguiente: "Actualmente existe un elenco de causas de inadmisión tasadas, cuya existencia debe comprobar el TC de oficio. La reforma prevé que sea el recurrente quien fundamente en su recurso la relevancia constitucional del caso que plantea ante el TC a efectos de la interpretación del Derecho Constitucional» (pág. 5).

14 Ley Orgánica 6/1988, de 9 de junio, que modifica el artículo 50 y 86.

15 Aunque no hay que perder de vista que en la práctica, no fue desdeñable que a partir del año 1988 conocieran las Secciones en vez de las Salas de la admisión de las demandas de amparo.

16 Nuevamente la Presidenta Casas hacía mención a este punto: «La combinación de los dos modelos daría como resultado un buen recurso de amparo. Aunque la formulación no sea la mejor, podría dar lugar a una interpretación correctora que, sin propiciar de nuevo el crecimiento de asuntos que llegan al Tribunal, no deje de proteger a un ciudadano al que se le ha lesionado un derecho fundamental. No se van a reducir las garantías". Ver entrevista en El Mundo de 8 de mayo de 2006.

17 Se incorporó a raíz de un voto particular in voce en el Senado del senador real Angulo Montes.

18 Ver LUCAS MURILLO DE LA CUEVA, P., "El amparo judicial de los derechos fundamentales" en G. RUIZ-RICO RUIZ (Ed.), La aplicación jurisdiccional de la Constitución, Valencia, Tirant Lo Blanch, 1997, págs. 120-121. 
siones judiciales y puede, también, cerrar el acceso al mismo para infracciones de derechos que no muestren la suficiente gravedad personal o relevancia objetiva ${ }^{19}$.

Para continuar con esta necesariamente breve contextualización de la reforma de la LOTC del año 2007, nos puede resultar ilustrativa a efectos prácticos, las Memorias anuales que realiza el Ministerio Fiscal. Respecto del año 2008, se refiriere a los efectos de la misma en los siguientes términos: "teniendo en cuenta que esos criterios que la ley marca acerca del concepto de "trascendencia constitucional" son generales y poco orientativos, y que por ahora el Tribunal Constitucional tampoco los define, corresponderá pues a la responsabilidad del Fiscal, valorar qué sea ese "algo más y distinto", con los criterios legales que contiene el artículo 50.1.b) LOTC, según el cual la especial trascendencia constitucional del recurso se apreciara atendiendo a su importancia para la interpretación, aplicación o general eficacia de la Constitución y para la determinación del contenido y alcance de los derechos fundamentales. Tal es la interpretación que la Fiscalía General del Estado ha sostenido en sendos escritos de 20 de julio de 2007 y 11 de abril de $2008^{20}$. En el presente año 2009, hay un importante avance en este sentido, pues se puede ya concretar más, tal y como se ve en su Memoria: "Sobre el requisito de justificar la especial trascendencia constitucional, el Tribunal ha establecido hasta la fecha (AATC 188/2008; 289/2008; 290/2008 y ATC de 9 de marzo de 2009):

- Que es una exigencia ineludible de las demandas de amparo.

- Que es de naturaleza sustantiva, como se refleja en la expresión "en todo caso" empleada por el artículo 49.1 de la LOTC.

- Que el incumplimiento de la exigencia a la que ahora nos referimos vicia a la demanda de amparo de un defecto insubsanable que conduce a su inadmisión a limine.

- Que la carga de justificar la especial trascendencia constitucional del recurso de amparo es algo [más y] distinto a razonar que la existencia de la vulneración de un derecho fundamental por resolución impugnada $w^{21}$.

En un estudio muy sólido sobre esta materia, Hernández Ramos nos advierte que "Con la nueva reforma de la LOTC de 2007 se produce una seria descoordinación entre la naturaleza constitucional del recurso de amparo, ins-

19 Ver J. JIMÉNEZ CAMPO: "Artículo 53 Protección de los derechos fundamentales" en Ó. ALZAGA (dir.) Comentarios a la Constitución Española de 1978, tomo IV, Madrid, Edersa/Cortes Generales, 1996, p. 510. Aunque nos advierte, a continuación que "más discutible es, sin embargo, que pueda hacer esto mismo el propio Tribunal Constitucional a partir de la actual regulación de la LOTC." Escribe esto el autor en el año 1996.

20 Ver Memoria anual del Ministerio Fiscal 2008, pág. 406, en www.fiscal.es

21 Ver Memoria anual del Ministerio Fiscal 2009, pág. 466, en www.fiscal.es 
trumento para tutelar principalmente los derechos subjetivos de los ciudadanos (art. 53.2 CE, art. 41.3 LOTC, art. 55.1 LOTC) y el trámite de admisión configurado a partir de la reforma de 2007 en términos objetivos ${ }^{22}$. Otros autores, como Matia Portilla, apuntan que el Legislador del 2007 no se decantó por la opción, ni más eficaz de cara al principal problema de saturación del Tribunal Constitucional, ni de mejor encaje constitucional, dado el carácter eminentemente subjetivo del art. 53.2 CE, ambas críticas son compartidas por Díaz Revorio ${ }^{23}$. Así, ve que "otra opción con claro encaje constitucional (y mucho más efectiva que la finalmente acogida por la LO 6/2007) sería entender que el recurso de amparo solamente debe estar disponible para revisar la actuación judicial cuando el propio ordenamiento jurídico atribuye la función judicial ordinaria a los tribunales de superior orden, ${ }^{24}$. Pero sin duda, el principal problema que afronta la reforma de la LOTC del 2007 es solventar conforme al artículo 53.2 CE el supuesto de inadmisión de amparo cuando se dé una violación de derechos y libertades fundamentales sin trascendencia constitucional. En este sentido, Oliva Santos indica que "nótese bien que sería legalmente procedente esa inadmisión aunque, prima facie y en comparación con casos semejantes, la demanda presentase, con documentación adjunta muchas veces, un caso en que el amparo habría de concederse. [...] a conse-

22 Ver M. HERNÁNDEZ RAMOS, El nuevo trámite de admisión del recurso de amparo constitucional, Madrid, Reus, 2009, p. 358-359. El trabajo constituye su tesis doctoral, lamentablemente se cerró antes de las resoluciones decisivas del Tribunal Constitucional sobre la materia, los autos del año 2008 y las dos sentencias del 2009, especialmente la 155/09. En el mismo realiza un estudio serio, con especial referencia al Tribunal Constitucional alemán y al Tribunal Supremo de los Estados Unidos. De hecho, la crítica citada se basa en la experiencia de estos tribunales. Continua el autor a este respecto: "De dejar así las cosas, el Tribunal Constitucional encontraría serias dificultades para cohonestar ambos procedimientos, admisión y estimación del recurso de amparo. Por ello, la función subjetiva del recurso de amparo ha de ser tenida en cuenta también en su trámite de admisión. Las experiencias del Tribunal Supremo de los Estados Unidos y del $B V \operatorname{erfG}$ muestran que, a pesar de que se han objetivado paulatinamente sus funciones, nunca ha dejado de tener en cuenta la protección subjetiva de los derechos fundamentales como criterio para admitir y conocer de un caso, aunque de una forma muy cualificada" (pág. 359).

23 Ver F. J. Díaz Revorio, "Tribunal Constitucional y procesos constitucionales en España: Algunas reflexiones tras la reforma de la Ley Orgánica del Tribunal Constitucional de 2007", en Estudios Constitucionales (Centro de Estudios Constitucionales de Chile), año 7, n 2, 2009, pág. 102. Así señala: "Queda por ver en qué medida se cumple el objetivo de descongestionar al Tribunal", y con anterioridad "La cuestión es si esta objetivación total, que resulta incuestionable tras la aprobación de la ley y las primeras sentencias que vienen a aplicarla, es compatible con la configuración constitucional del recurso de amparo".

24 Ver F. J. MATIA PORTILLA, "La especial trascendencia constitucional y la inadmisión del recurso de amparo", en Revista Española de Derecho Constitucional, n 86, 2009, pág. 348. Continúa argumentando su propuesta: “Podría así entenderse que solamente fueran impugnables en amparo las resoluciones dictadas por determinados órganos judiciales (Tribunal Supremo, Audiencia Nacional, Tribunales Superiores de Justicia). Tal opción provocaría una relevante caída en el número de amparos. No tiene este efecto, eso es claro, la opción de que debe justificarse la especial trascendencia constitucional. Los abogados cumplirán en breve, si no lo están haciendo ya, con la carga procesal impuesta, y los Magistrados deberán ponderar si aquélla concurre o no en cada caso, por lo que el tiempo invertido en el examen de los asuntos no seré menor que el actualw. 
cuencia de la LO 6/2007, las violaciones de libertades y derechos fundamentales referidos en el art. 53.2 CE dejan de ser relevantes para el TC, dejan de ser amparables por el TC, si no son constitucionalmente interesantes "25.

Concluimos, la reforma de la LOTC de 2007 ha tenido básicamente dos modelos, en menor medida el americano y el poder discrecional que su Tribunal Supremo tiene - writs of certiorari - para atender tan sólo aquellos casos más relevantes subjetiva - de manera minoritaria-y objetivamente. Y el caso que más ha influido en nuestro legislador, el del Tribunal Constitucional alemán, cuya saturación "intento ser solucionada a través de múltiples reformas por las que se agravaban los requisitos de admisión de los recursos, tanto en un sentido subjetivo como en uno objetivo, y se dotaba al Alto Tribunal de un mayor margen de libertad en la valoración de los criterios de admisión. Sin embargo, llegó un momento, como constató la Comisión Benda, en el que ya no era posible flexibilizar más el trámite de admisión sin dar entrada a un sistema de corte discrecional como el del Tribunal Supremo Federal estadounidense ${ }^{26}$. Al final se optó en Alemania por "seguir reconociendo un derecho a los ciudadanos de acceder a la jurisdicción del $B V e r f G$, pero dando protagonismo a aquellos recursos que plantearan cuestiones especialmente trascendentales tanto en un sentido objetivo como en un sentido subjetivo" ${ }^{27}$.

\section{EL ANTECEDENTE DE LOS AATC DE 2008 Y LA STC 70/2009, DE 23 DE MARZO}

La reforma de la LOTC de 2007 produjo en todos los operadores jurídicos una profunda inseguridad jurídica pues formalmente no sólo invierte el juicio de admisibilidad, si no que todo lo hace depender de un concepto jurídico indeterminado al que no se le dota de contenido: la "especial trascendencia constitucional". Las dificultades aumentan cuando la LO 6/2007 no tiene vacatio legis y entra en vigor al día siguiente de su publicación en el BOE, esto es, el 27 de mayo de 2007. Por lo demás, es en marzo de 2009 cuando encontramos el primer esbozo de determinación del concepto «especial trascendencia constitucional" por parte del Tribunal Constitucional, que se perfila más detalladamente en junio de ese año con la STC 155/2009. Por tanto, más de dos años ha tardado el Tribunal Constitucional en señalarnos qué debemos entender por este decisivo concepto para la admisión de la demanda

25 Ver A. DE LA OLIVA SANTOS, “La perversión jurídica del amparo...”, ob. cit., pág. 19. Proponiendo el autor como posible solución lo siguiente: "para evitar desamparar lo amparable, [...] el TC podría entender que entrar a conocer del fondo de esos recursos, tras admitirlos, entraña una innegable y "especial trascendencia constitucional" [...]. De ese modo, no se dejarían sin amparo casos claros in limine de violación de libertades y derechos fundamentales" (pág. 21).

26 Ver M. HERNÁNDEZ RAMOS, ob. cit., pág. 7.

27 Ibidem. Bien es verdad que la dedicación a la tutela subjetiva de los derechos tras la reforma es mínima. BVerfG es la abreviatura de Bundesverfassungsgericht, que es la denominación del Tribunal Constitucional Federal alemán. 
de amparo. A continuación describiremos cómo paulatinamente el Tribunal Constitucional ha ido aportando elementos interpretativos, comenzando con los ya citados Autos del año 2008.

En el Auto 188/2008, de 21 de julio (Sala 1a), destacamos dos ideas. Primero en su fundamento jurídico $1^{\circ}$ lo que es la clave de la reforma de la LOTC de 2007, la exigencia de que el recurrente justifique la especial trascendencia constitucional y que, posteriormente, el Tribunal aprecie o considere que efectivamente se da: "el recurso de amparo, conforme a lo dispuesto en el art. 50.1.a) LOTC, no puede ser admitido a trámite si el recurrente no cumple - además de los restantes requisitos procesales previstos en los arts. 42-44 LOTC - la ineludible exigencia impuesta por el art. 49.1 in fine LOTC de justificar de manera expresa en la demanda de amparo la especial trascendencia constitucional del recurso, cuya naturaleza sustantiva se refleja en la expresión "en todo caso" empleada por el precepto. Ello sin perjuicio, claro está, de la apreciación por parte de este Tribunal, atendiendo a los criterios señalados por el art. 50.1.b) LOTC acerca de si, cumplida aquella exigencia por el recurrente, el recurso de amparo reviste efectivamente una especial trascendencia constitucional que justifique una decisión sobre el fondo por parte del Tribunal Constitucional». Segundo, también relevante, en su fundamento jurídico $3^{\circ}$ se refiere a la especial trascendencia constitucional como "un requisito insubsanable, [...] no siendo, en consecuencia, procedente la apertura del trámite de subsanación previsto en el art. 49.4 LOTC".

El Auto 289/2008, de 22 de septiembre (Sala $2^{\mathrm{a}}$ ), continua la línea iniciada por el anterior estudiado ${ }^{28}$, pero tiene el especial interés del voto particular del magistrado Gay Montalvo, que aborda directamente el problema que suscita la interpretación del requisito de especial trascendencia constitucional y de los también abiertos e indeterminados criterios legales del artículo 50.1.b) LOTC, a saber: atendiendo a su importancia para 1. La interpretación de la Constitución, 2. Para su aplicación o para su general eficacia, y para 3. La determinación del contenido y alcance de los derechos fundamentales. Quizás demasiada indeterminación para un concepto y unos criterios tan relevantes en cuanto a la admisión o no del recurso de amparo del cual, en teoría, conforme al artículo $53.2 \mathrm{CE}$, todos los ciudadanos tenemos derecho a obtener la resolución al respecto de nuestro más alto Tribunal.

La base del argumento del voto particular es que la interpretación que el Tribunal Constitucional hace de la nueva reforma de la LOTC — discrepa pues con la interpretación, no con la reforma legal- es contraria "a la finalidad esencial del recurso de amparo que es la protección en sede constitucional de los derechos y libertades, cuando las vías ordinarias de protección han resultado insatisfactorias". No comparte pues la objetivación del recurso

28 No hay pues discrepancia entre las Salas, sin embargo, cuando llega al Pleno, caso de la STC 155/2009, la discrepancia inicial del magistrado Gay Montalvo se mantiene en cuanto al fundamento jurídico $2^{\circ}$ y se incorpora, como veremos, el voto discrepante del magistrado RodríguezZapata. 
"en detrimento de una concepción subjetiva", pues estima que no encaja con "Su diseño constitucional y procesal". Para concluir expresando el quiz de la cuestión: «Me pregunto, en fin, si por razones de carga y organización de trabajo del Tribunal Constitucional, puede llegarse, de seguirse la interpretación realizada, a la desatención de la alta función que, en materia de tutela de los derechos fundamentales, nos corresponde".

Por último, también se refiere al ya citado carácter insubsanable del nuevo requisito para la demanda de amparo, viendo como "en numerosas ocasiones y en atención a circunstancias diversas, hemos defendido que determinados requisitos deben ser interpretados de manera flexible y finalista [...]. Pues bien, en el presente caso y dado que la Ley Orgánica 6/2007 no incorpora un periodo de vacatio legis, considero que el Tribunal Constitucional en asunción de su función de protección de los derechos fundamentales no podía menos que mostrar una mayor flexibilidad".

Nos resta ${ }^{29}$, antes de entrar en la decisiva STC $155 / 2009$, ver brevemente su antecedente, en la STC 70/2009, de 23 de marzo. En efecto, el primero de los siete supuestos que dotan de contenido o determinan qué es la especial trascendencia constitucional que fija, no de forma exhaustiva, ni cerrada el Tribunal Constitucional en la STC $155 / 2009$, ya lo encontramos en el fundamento jurídico primero de la STC 70/2009 en los siguientes términos: «Este óbice de admisibilidad debe rechazarse. En primer lugar, porque tal justificación se contiene en la demanda de amparo y porque, además, concurre la especial trascendencia constitucional a la que se refiere, dado que se trata de una cuestión en la que este Tribunal no ha sentado doctrina". Por tanto, ya marca el Tribunal que hay especial trascendencia constitucional cuando sobre la materia objeto del recurso el Tribunal no ha sentado doctrina. Queda patente el carácter objetivo que adquiere el recurso de amparo tras la reforma de la LOTC de 2007 sobre su dimensión subjetiva. No sólo en cuanto a su regulación legal, si no también a la línea interpretativa que el Tribunal Constitucional comienza a trazar y se consolida en la STC 155/2009, de 25 de junio.

\section{LA DETERMINACIÓN DEL CONCEPTO EN LA STC 155/2009, DE 25 DE JUNIO}

El itinerario ${ }^{30}$ en lo que es la concreción del concepto jurídico indeterminado "especial trascendencia constitucional" llega su puerto, por el mo-

29 Otros Autos que van en la línea de los estudiados, son AATC 290/2008, de 22 de septiembre; 166/2009, de 27 de mayo; y 165/2009, de 25 de mayo.

30 Este itinerario se inicia con la propia reforma del art. 50.1.b) LOTC del año 2007 al señalar que se «apreciará atendiendo a su importancia para la interpretación de la Constitución, para su aplicación o para su general eficacia, y para la determinación del contenido y alcance de los derechos fundamentales". El segundo paso significativo lo encontramos en los dos Autos del año 2008 estudiados en el apartado III. Y por último, el tercer paso previo a la Sentencia $155 / 2009$ es la STC $70 / 2009$, de 23 de marzo. 
mento definitivo ${ }^{31}$, con la STC $155 / 2009$, de 25 de junio ${ }^{32}$. A lo largo de este trabajo hemos visto como los diferentes operadores jurídicos (fiscales, abogados, etc.) demandaban del Tribunal Constitucional ${ }^{33}$ una determinación de este concepto tan decisivo para la admisión de la demanda de amparo constitucional desde la reforma de la LOCT de 2007. E incluso muchas críticas iban en este sentido, que estimamos que con esta importante ${ }^{34}$ Sentencia, quedan ya bastante amortiguadas, pero posiblemente no del todo, como a continuación veremos.

De entrada, el fundamento jurídico $2^{\circ}$, sin duda el más relevante para nuestro estudio, nos indica lo siguiente: "el carácter notablemente abierto e indeterminado, tanto de la noción de "especial trascendencia constitucional", como de los criterios legalmente establecidos para su apreciación". Por tanto el Tribunal Constitucional es consciente de que estamos ante un concepto jurídico indeterminado que en esta resolución trata de determinar de manera importante, y también de la indeterminación de los criterios apuntados en el art. 50.1.b) in fine de la LOTC, a saber: "apreciará atendiendo a su importancia para la interpretación de la Constitución, para su aplicación o para su general eficacia, y para la determinación del contenido y alcance de los derechos fundamentales". Aunque realmente la Sentencia se centra en el primer supuesto, sobre el que pivota la esencia de la reforma de la LOTC del año 2007.

La clave para la determinación básicamente del concepto jurídico indeterminado "especial trascendencia constitucional" la encontramos en el fundamento jurídico $2^{\circ}$, que nos dice: "Tales casos serán los siguientes: a) el de un recurso que plantee un problema o una faceta de un derecho fundamental susceptible de amparo sobre el que no haya doctrina del Tribunal Constitucional, supuesto ya enunciado en la STC 70/2009, de 23 de marzo; b) o que dé ocasión al Tribunal Constitucional para aclarar o cambiar su doctrina, como consecuencia de un proceso de reflexión interna, como acontece en el

31 La propia dinámica de los conceptos jurídicos indeterminados lleva a que posteriores sentencias del Tribunal Constitucional puedan ir perfilando aún más su contenido, para el estudio de otros conceptos en los que esto ha sucedido, ver D. ORTEGA GUTIÉRREZ, Los conceptos jurídicos indeterminados en la jurisprudencia constitucional española, ob. cit., págs. 26-109.

32 Sentencia avocada por el Pleno para fijar el alcance y significado de la especial transcendencia constitucional", en este caso concreto en relación con la configuración del principio acusatorio en la doctrina constitucional.

33 El propio magistrado del TC Gay Montalvo así lo reconocía en su voto particular al ATC $289 / 2008$.

34 Algunos autores, como PULIDO QUECEDO, entienden que el Tribunal se ha extralimitado en sus funciones de intérprete, viendo como el fundamento jurídico segundo crea una nueva categoría de sentencia-normativa, dado su trascendente valor normativo-interpretativo, pues más que precisar los criterios del art. 50.1 LOTC, los complementa. Viendo incluso la pertinencia de una aplicación, a mi entender algo forzada, del art. 2.2 LOTC para que en uso de su potestad reglamentaria, el Tribunal hubiera adoptado un Acuerdo para dotar de contenido al concepto. Ver M. PULIDO QUECEDO, "El requisito de "la especial trascendencia constitucional" en el recurso de amparo", en Revista Aranzadi Doctrinal, no 6 (2009), pág. 3. 
caso que ahora nos ocupa, o por el surgimiento de nuevas realidades sociales o de cambios normativos relevantes para la configuración del contenido del derecho fundamental, o de un cambio en la doctrina de los órganos de garantía encargados de la interpretación de los tratados y acuerdos internacionales a los que se refiere el art. 10.2 CE; c) o cuando la vulneración del derecho fundamental que se denuncia provenga de la ley o de otra disposición de carácter general; d) o si la vulneración del derecho fundamental traiga causa de una reiterada interpretación jurisprudencial de la ley que el Tribunal Constitucional considere lesiva del derecho fundamental y crea necesario proclamar otra interpretación conforme a la Constitución; e) o bien cuando la doctrina del Tribunal Constitucional sobre el derecho fundamental que se alega en el recurso esté siendo incumplida de modo general y reiterado por la jurisdicción ordinaria, o existan resoluciones judiciales contradictorias sobre el derecho fundamental, ya sea interpretando de manera distinta la doctrina constitucional, ya sea aplicándola en unos casos y desconociéndola en otros; f) o en el caso de que un órgano judicial incurra en una negativa manifiesta del deber de acatamiento de la doctrina del Tribunal Constitucional (art. 5 de la Ley Orgánica del Poder Judicial: LOPJ); g) o, en fin, cuando el asunto suscitado, sin estar incluido en ninguno de los supuestos anteriores, trascienda del caso concreto porque plantee una cuestión jurídica de relevante y general repercusión social o económica o tenga unas consecuencias políticas generales, consecuencias que podrían concurrir, sobre todo, aunque no exclusivamente, en determinados amparos electorales o parlamentarios".

Por lo tanto, el Tribunal Constitucional ofrece siete supuestos que dan contenido o determinan el contenido de lo que debemos entender por "especial trascendencia constitucional. . Como el propio Tribunal apunta, el primero de ellos ya lo había avanzado en la STC de 23 de marzo de 2009.

Lo primero que debemos apuntar es que no estamos ante una determinación definitiva ni cerrada, pudiendo por tanto ampliarse o reducirse. Así nos lo indica el Tribunal en el mismo fundamento jurídico $2^{\circ}$ : "sin que la relación que se efectúa pueda ser entendida como un elenco definitivamente cerrado de casos en los que un recurso de amparo tiene especial trascendencia constitucional, pues a tal entendimiento se opone, lógicamente, el carácter dinámico del ejercicio de nuestra jurisdicción, en cuyo desempeño no puede descartarse a partir de la casuística que se presente la necesidad de perfilar o depurar conceptos, redefinir supuestos contemplados, añadir otros nuevos o excluir alguno inicialmente incluido". Este carácter dinámico en la determinación de los conceptos jurídicos indeterminados deriva lógicamente del papel constitutivo de los mismos que la casuística siempre desempeña en esta materia.

De los siete supuestos indicados por el Tribunal para determinar la especial trascendencia constitucional, que posibilita que éste pueda conocer de una demanda de amparo, se pueden realizar las siguientes apreciaciones. El primero marca el caso de la laguna doctrinal del Tribunal, ausencia que en materia de protección de derechos parece justificado que dé contenido a la 
especial trascendencia constitucional, pues nos hayamos ante un nuevo supuesto de la realidad que afecta a la interpretación de un derecho fundamental y el Tribunal no se había manifestado nunca sobre el mismo. Nuevamente aparece la casuística como un elemento vivificador del Derecho que obliga necesariamente al Tribunal a pronunciarse, dada la importancia o relevancia de dar respuesta constitucional a la nueva realidad.

El segundo supuesto no se centra en la novedad si no en el cambio o evolución en la comprensión de un derecho. Este cambio puede ser fruto de cuatro realidades que el Tribunal nos describe: 1 . Una evolución interna del Tribunal en su comprensión del derecho en cuestión —de todos los supuestos el más genérico y abierto, y que deja las manos libres al Tribunal Constitucional en su labor interpretativa en materia de amparo-, o puede venir marcado externamente, bien 2. Por cambios sociales o 3. Normativos, bien por 4. Pautas marcadas básicamente en materia de derechos, por el Tribunal Europeo de Derechos Humanos, de largo el más citado e influyente en las propias resoluciones del Tribunal Constitucional.

El tercer caso se refiere al recurso que resulte de la labor o actividad de un poder público, concretamente el poder legislativo. Parece razonable que la posible vulneración de un derecho fruto de una ley tenga la consideración de especial trascendencia constitucional. El siguiente supuesto o letra d) surge de la necesidad de cambiar una interpretación reiterada y errónea de la ley, que resulta lesiva para el ejercicio o disfrute de un derecho. En el tercer caso o letra c) la lesión del derecho nace de la ley, en el cuarto o letra d) nace de la interpretación que el Tribunal Constitucional venía haciendo de manera reiterada de la ley.

El quinto caso o letra e) es algo desconcertante en un Estado de Derecho, pues se basa en que el poder judicial, globalmente como tal, no respete el artículo 1.1 de la LOTC, que dice: "El Tribunal Constitucional, como interprete supremo de la Constitución...". Si el artículo 1 señala que es el intérprete supremo, parece lógico que el poder judicial atienda y respete este artículo de la LOTC. A mayor abundamiento el artículo 5 de la Ley Orgánica 6/1985, de 1 de julio, del Poder Judicial, indica que "los Jueces y Tribunales interpretarán y aplicarán las leyes y reglamentos según los preceptos y principios constitucionales, conforme a la interpretación de los mismos que resulte de las resoluciones dictadas por el Tribunal Constitucional". Junto a este caso, incluye también las interpretaciones contradictorias sobre un derecho. En este supuesto se entiende que el Tribunal Constitucional, y en eso consistirá la especial trascendencia constitucional, tendrá que determinar cuál es la correcta conforme a la Constitución de las dos o más interpretaciones que estén en contradicción. Resulta algo raro que la inaplicación se considere como una parte de la contradicción, como parece deducirse de la redacción de la letra e), a no ser que desconocer se asemeje a contradictorio, algo por lo demás difícilmente asumible.

El siguiente supuesto o letra f) no es tan alarmante para el Estado de Derecho como el anterior, pero desde luego no es tranquilizador que un órgano 
judicial no respete el ordenamiento jurídico y la función constitucional del denominado poder corrector. Los argumentos son los mismos que para el caso anterior o letra e). En alguna medida el supuesto f) no deja de ser una concreción del más genérico supuesto e), la diferencia parece estribar en la cantidad, en el supuesto quinto es global, en el sexto es de un órgano judicial concreto. En ambos casos el poder judicial, uno o muchos de sus órganos, incumplen el ordenamiento jurídico, lo que implicaría estudiar la posibilidad de si cabe, según el caso, la correspondiente aplicación del artículo $133^{35}$ de la citada LOPJ.

Por último, la letra g) o séptimo supuesto no deja de ser una especie de cajón de sastre que incurre en el nada infrecuente caso, dentro de los conceptos jurídicos indeterminados, en que se utilizan nuevamente otros conceptos jurídicos indeterminados para definirlos. Así, la eespecial trascendencia constitucional" se define por una cuestión jurídica de "relevante y general repercusión social o económica" o tenga "consecuencias políticas generales". Las preguntas son obvias, ¿qué debemos entender por "relevante y general repercusión social o económica"?, ¿Y por "consecuencias políticas generales"? Parece incluso que el Tribunal Constitucional es consciente de estar determinando el concepto jurídico indeterminado "especial trascendencia constitucional" con otros conceptos jurídicos indeterminados, y así avanza en relación con el segundo alguna concreción, al señalar que se considerará como "consecuencias políticas generales" las referidas a amparos en materia parlamentaria o electoral.

\section{CONCLUSIONES}

Se puede observa que, en importante medida, en la STC 155/2009 no se dan las pautas interpretativas habituales en materia de conceptos jurídicos indeterminados, probablemente por la propia particularidad del concepto en sí, de su nacimiento y de su finalidad. No encontramos, en primer lugar, la función usual que en esta materia juega la relevancia de la casuística, que es la base que normalmente utiliza el Tribunal Constitucional para, a partir del conocimiento de la realidad de cada caso concreto, ir perfilando o extrayendo el denominador común que dote de contenido al concepto jurídico indeterminado, como el Tribunal Constitucional ha hecho, por ejemplo, con otros conocidos conceptos jurídicos indeterminados (como tutela judicial efectiva, dilaciones indebidas, motivación suficiente o justa causa). En la Sentencia 155/2009, el Tribunal Constitucional hace en alguna medida lo contrario, en vez de seguir un proceso de lo particular a lo general o inductivo, marca un proceso deductivo, con siete supuestos por él contemplados a priori o de manera teórica, a los que se deben adaptar o encajar aquellas demandas de recursos de amparo que busquen prosperar.

35 Art. 133: "A la Comisión Disciplinaria corresponde la competencia para la instrucción de expedientes e imposición de sanciones a Jueces y Magistrados". 
También resulta extraño, en segundo lugar, pues suele suceder con frecuencia en la concreción o determinación que el Tribunal Constitucional hace de los conceptos jurídicos indeterminados, el no señalar qué no debe entenderse por ellos, algo que no carece de utilidad, esto es, avanzar lo que no debe entenderse por ese concepto. Es evidente que en el concepto que nos ocupa, podría ser interminable la lista de los casos que obviamente no tienen especial trascendencia constitucional, pero no será extraño que en el futuro nos vayamos encontrado sentencias del Tribunal que nos indiquen los casos límite o dudosos entre lo que es y no es especial trascendencia constitucional. La propia casuística, en esta perspectiva curiosamente sí, irá marcando la necesidad de la aparición de la siempre útil definición en negativo. No obstante a lo indicado, sí podríamos encontrar una definición en negativo — por tanto, qué no es especial trascendencia constitucional - de manera colateral en la letra g) del fundamento jurídico segundo, cuando el Tribunal apunta que "el asunto suscitado [...] trascienda del caso concreto". La no trascendencia del caso concreto determina el no tener especial trascendencia constitucional y por tanto la no admisión del recurso de amparo. Esto en cierta medida muestra el carácter objetivo que prevalece tanto en la reforma del año 2007 como en la jurisprudencia del Tribunal Constitucional. Por último, sí encontramos algo frecuente que sucede en la determinación de los conceptos jurídicos indeterminados, esto es, el remitirse a su vez a otros conceptos jurídicos indeterminados - como hace el séptimo supuesto del fundamento jurídico segundo estudiado-.

A la luz de lo analizado en este trabajo, es difícilmente discutible la situación de inseguridad jurídica creada por la combinación de los siguientes elementos: 1. Una nueva exigencia fruto de la reforma de los arts. $49.1 \mathrm{y}$ 50.1.b) de la LOTC centrada en un concepto jurídico indeterminado: la especial trascendencia constitucional; 2 . La ausencia de vacatio legis de la citada reforma legal, con la inmediat ${ }^{36}$, por tanto, entrada en vigor de la reformada LOTC; 3. Los más de dos años que ha tardado el Tribunal Constitucional de dotar o determinar qué debemos entender por especial trascendencia constitucional, con la STC 155/2009. Así nos lo manifestaba en este iter el magistrado Gay Montalvo en su voto particular al Auto 289/2008, al señalar que "al no haberse realizado todavía dicha concreción por quienes estamos llamados a ello, difícilmente puede exigirse al recurrente que, en atención a lo previsto en el art. 53.2 CE, acredite la concurrencia de un requisito cuyo contenido desconoce, con toda la carga de inseguridad que ello conllevan; y 4. Una interpretación rígida de los nuevos requisitos de los arts. 49.1 y 50.1.b) por parte del Tribunal Constitucional.

Nos encontramos ante un concepto jurídico indeterminado sui generis, especialmente por la especial y determinante función que le toca desempeñar

36 Que algunos autores, no sin razón, han calificado de precipitada, entre otros, I. BORRAJO INIESTA y C. ELÍAS MÉNDEZ, "La puesta en marcha del nuevo recurso de amparo y otras facetas de la jurisprudencia constitucional", en Revista General de Derecho Constitucional 8 (2009), pág. 2. 
dentro de la finalidad de la reforma de la LOTC de 2007. Normalmente los conceptos jurídicos indeterminados que afronta el Tribunal Constitucional para su determinación están en la propia Constitución, como por ejemplo: tutela judicial efectiva, dilaciones indebidas, intereses legítimos, plazo máximo de duración, insuficiencia de recursos para litigar, error judicial, servicios esenciales, etc. Pero en este caso estamos ante un concepto de base legal, fruto del Legislador, no del constituyente, pero que puede vulnerar lo marcado por el constituyente, especialmente en su artículo 53.2 CE. Así, corresponde al Tribunal Constitucional una labor muy complicada, pues le afecta a sí mismo, siendo juez y parte. Se mezcla la propia carga de su trabajo y eficacia en sus funciones, con dotar del contenido correcto a este concepto jurídico indeterminado, respetando el 53.2 CE. No es por lo tanto un concepto jurídico indeterminado regulado en la CE, pero la determinación que de él se haga puede afectar directamente a uno de los Institutos más importantes de la CE, referido a la defensa de los derechos y libertades de los ciudadanos.

La sistematización del fundamento jurídico segundo de la STC 155/2009, no es sin duda la mejor. De entrada, los siete supuestos teóricos, en realidad son bastantes más y además mezclados entre sí, con un último supuesto que hace las veces de cajón de sastre. Hay que apreciar, cómo no, la labor del Tribunal en este esfuerzo por racionalizar su trabajo y funciones, pero seguro que vendrán futuras sentencias que acoten y sistematicen la comprensión de este concepto jurídico indeterminado, de cuya correcta interpretación, en última instancia, depende la eficaz protección de nuestros derechos fundamentales. Y no sería raro, que encontráramos una evolución jurisprudencial, si quiera mínima, al reconocimiento del carácter subjetivo del recurso de amparo, al menos para los supuestos más graves y evidentes, en concordancia con lo contemplado en el art. 53.2 CE.

Es evidente que el Tribunal Constitucional precisaba racionalizar el exceso de demandas de amparo, pues de las admitidas, más del 97\% de las mismas se desestiman, por tanto la jurisdicción ordinaria ha demostrado en estas tres décadas que realiza bien su trabajo de protección de los derechos fundamentales y libertades públicas del ciudadano. Obviamente el único problema que se plantea ahora es encauzar ese cerca de $2 \%$ de demandas de amparo de los ciudadanos, que conforme a la concepción subjetiva clara que se deriva del artículo 53.2 CE, sí tienen derecho a acceder a la justicia constitucional. Entiendo que la jurisprudencia futura del Tribunal Constitucional, tendrá que ir dotando de contenido adecuado al concepto jurídico indeterminado especial trascendencia constitucional". No poco hemos avanzado, ya iba siendo necesario desde la reforma de la LOTC de 2007, con la STC 155/2009.

Por lo demás, estimo que dentro de la objetivación operada por la citada reforma y la posterior interpretación constitucional de nuestro más alto Tribunal, el único camino que veo para tratar de mantener viva la concepción subjetiva del recurso de amparo y la defensa de los derechos de los ciudadanos, es la interpretación de la "especial transcendencia constitucional" conforme al supuesto de la letra f) de la STC 155/2009. Creo que esa vía sería la más acorde 
con la realidad o casuística que suele fundar normalmente las demandas de amparo, existiendo ya - como sucede en España—, una doctrina constitucional bastante extensa y "consolidada, ${ }^{37}$ en materia de derechos fundamentales y libertades públicas. La negativa pues del Tribunal ordinario a aplicarla, sería el argumento demostrativo de la especial trascendencia constitucional.

Por último, resta por esperar que funcione el efecto disuasorio de dicha reforma, para que no lleguen al Tribunal Constitucional ese exceso de litigiosidad de amparo poco fundado de la ciudadanía española - y que tanto ha paralizado y saturado el trabajo del Tribunal-, pero que la interpretación de la "especial transcendencia constitucional", que no me parece un filtro inadecuado, no deje fuera a quien sí tiene el derecho constitucional de amparo reconocido en el art. 53.2 CE. Estimo que éste es el reto que tiene el Tribunal que afrontar en estos años y la clave será el contenido o determinación que vaya dando al concepto, y por qué no decirlo de una vez, por polémico que pueda resultar, el uso más responsable y fundado que todos hagamos del amparo constitucional, pues es claro que un uso inadecuado ${ }^{38}$ o no fundado produce el efecto paralizador del Tribunal, que a la larga a todos nos perjudica con una justicia constitucional más lenta, y ahora en especial, a ese más de $2 \%$ que sí tiene razón en su demanda de amparo y puede quedar fuera del filtro que supone la "especial transcendencia constitucional".

TitLE: The "special constitutional significance" as indeterminate legal concept. From 2007 LOTC reform to the STC 155/2009.

ABSTRACT: This article examines the reform of the Organic Law of the Constitutional Court (OLCC) in 2007 regarding the requirements in order to accept the appeal for constitutional protection and, specifically, the term "special constitutional significance" listed in articles 49 and 50 of the OLCC, and the interpretation of it as the STC 155/2009 indeterminate legal concept does.

Resumen: En el presente artículo se estudia la reforma de la Ley Orgánica del Tribunal Constitucional (LOTC) del año 2007 en lo que afecta a los requisitos para admitir la demanda de amparo constitucional y, concretamente, la expresión "especial trascendencia constitucional" que recogen los artículos 49 y 50 de la LOTC, y la interpretación que de la misma hace la STC 155/2009 como concepto jurídico indeterminado.

KEY WORDS: Indeterminate legal concept. Special constitutional significance. Admission of appeal for constitutional protection.

Palabras clave: Concepto jurídico indeterminado. Especial transcendencia constitucional. Admisión demanda de amparo constitucional.

37 En la propia reforma de la LOTC de 2007, la doctrina consolidada ha servido para descargar competencias de las Salas a las Secciones. Ver art. 52.2.

38 Teniendo presente que poco más del $2 \%$ de los recursos de amparo prosperan, cabría preguntarse por la deontología de los letrados a la hora de asesorar a sus representados o del uso dilatorio para retardar una sentencia inevitablemente negativa. 